\title{
Peripheral Markers of Serotonergic and Noradrenergic Function in Post-Pubertal, Caucasian Males with Autistic Disorder
}

Jan Croonenberghs, M.D., Laure Delmeire, M.D., Robert Verkerk, Ph.D., Ai-hua Lin, M.D., M.Sci., Anisa Meskal, Ph.D., Hugo Neels, Ph.D., Marc Van der Planken, M.D., Ph.D., Simon Scharpe, Ph.D., Dirk Deboutte, M.D., Ph.D., Greet Pison, Ph.D., and Michael Maes, M.D., Ph.D.

Some studies have suggested that disorders in the peripheral and central metabolism of serotonin (5-HT) and noradrenaline may play a role in the pathophysiology of autistic disorder. This study examines serotonergic and noradrenergic markers in a study group of 13 male, postpubertal, caucasian autistic patients (age 12-18 y; I.Q. > 55) and 13 matched volunteers. $\left[{ }^{3} \mathrm{H}\right]$-paroxetine binding $\mathrm{Kd}$ values were significantly higher in patients with autism than in healthy volunteers. Plasma concentrations of tryptophan, the precursor of 5-HT, were significantly lower in autistic patients than in healthy volunteers. There were no significant differences between autistic and normal children in the serum concentrations of 5-HT, or the 24-hr urinary excretion of 5-hydroxy-indoleacetic acid (5-HIAA), adrenaline, noradrenaline, and dopamine. There were no significant differences in $\left[{ }^{3} \mathrm{H}\right]$-rauwolscine binding Bmax or $K d$ values, or in the serum concentrations of tyrosine, the precursor of noradrenaline, between both study groups. There were highly significant positive correlations between age and 24-hr urinary excretion of 5-HIAA and serum tryptophan. The results suggest that: 1) serotonergic disturbances, such as defects in the 5-HT transporter system and lowered plasma tryptophan, may play a role in the pathophysiology of autism; 2) autism is not associated with alterations in the noradrenergic system; and 3) the metabolism of serotonin in humans undergoes significant changes between the ages of 12 and 18 years.

[Neuropsychopharmacology 22:275-283, 2000] (c) 2000 American College of Neuropsychopharmacology. Published by Elsevier Science Inc.
From the University Center of Child and Adolescent Psychiatry, A.Z.M., Antwerp, Belgium (JC, DD); the Clinical Research Center for Mental Health (CRC-MH), Antwerp, Belgium (LD, A-hL, MM); Department of Medical Biochemistry (RV, A-hL, SS) and Department of Mathematics and Computerized Sciences, University of Antwerp (GP), Wilrijk, Belgium; Department of Clinical Biochemistry, A.Z.M, Antwerp, Belgium (AM, HN); Department of Hematology, University Hospital of Antwerp, Edegem, Belgium (MVdP); Department of Psychiatry, Vanderbilt University, Nashville, TN, USA (MM); IRCCS, Istituto Fatebenefratelli, Brescia, Italy (MM); and Department of Psychiatry and Neuropsychology, University Hospital of Maastricht, Maastricht, The Netherlands (MM).

Address correspondence to: Jan Croonenberghs, M.D., University Center of Child and Adolescent Psychiatry, A.Z. Middelheim, Lindendreef 1, 2020, Antwerp, Belgium.

Received January 15, 1999; revised May 25, 1999; accepted September 25, 1999.
KEY WORDS: Autism; Serotonin; Norepinephrine; Tryptophan; Age; Tyrosine; Serotonin transporter; Paroxetine binding

\section{INTRODUCTION}

Autism is a pervasive developmental disorder. The core symptoms and diagnostic criteria according to the DSM- III-R and DSM-IV (American Psychiatric Association 1987, 1994) are a qualitative impairment in social interaction and language and restricted repetitive and stereotyped patterns of behaviour, interest, and activities. The condition is highly prevalent 
(5-15 per 10.000) and is four times more common in boys than in girls. Research on the biological pathophysiology of autism has found some evidence for a role of the turnover of serotonin (5-HT) and catecholamines.

\section{Serotonin $(5-\mathrm{HT})$}

Blood concentrations of serotonin (5-HT) are increased in a subgroup of autistic children (Schain and Freedman 1996; Cook and Leventhal 1996). McBride et al. (1998) found that the autistic group showed a modest $(15 \%)$ elevation in whole blood 5-HT which might have proved statistically significant in a larger study group. However, expressed as platelet volume, the mean 5-HT values for the post-pubertal autistic group was slightly lower than that for the control group, suggesting that hyperserotonemia is more prevalent in prepubertal than post-pubertal autistic individuals. Hanley et al. (1977) found that about one-half of the children who are not autistic but severely retarded show hyperserotonemia.

The discrepancy between the McBride et al. (1998) and the Hanley et al. (1977) studies might be explained by the lack of well-established exclusion criteria for autism in the mentally retarded subjects when subjects were seen in the 1960's. Selective 5-HT reuptake inhibitors (SSRIs), have beneficial effects in the treatment of some individuals with autism (McDougle et al. 1996a). Tryptophan depletion techniques result in a significant increase in autistic behaviours (McDougle et al. 1996b). PET-scan studies revealed decreased 5-HT synthesis in frontal cortex and thalamus, but elevated 5-HT synthesis in the contra-lateral dentate nucleus (Chugani et al. 1997).

The normal developmental process, that humans undergo a period of high brain 5 -HT synthesis capacity until the age of 5 years, may be disrupted in autistic children (Chugani et al. 1999). There is some preliminary evidence of linkage and association between the 5-HT transporter gene and autistic behavior. There are, however, discrepancies between the work of Cook et al. (1997) and Klauck et al. (1997) who found an association to the long rather than the short allele of the 5-HT transporter gene in autistic subjects. It has remained elusive, however, whether platelet paroxetine binding characteristics are altered in autism (Cook et al. 1993).

Findings concerning tryptophan, the precursor of 5-HT, the competing amino acids, and the ratio of tryptophan to amino acids known to compete for the same cerebral uptake site (competing amino acids, CAA), have been inconsistent (Johnson et al. 1974; Jackson and Garrod 1978; Perry et al. 1978; Winsberg et al. 1980; Hamberger et al. 1982; Hoshino et al. 1986; Minderaa et al. 1989; Visconti et al. 1994; D'Eufemia et al. 1995; McDougle et al. 1996a). Total plasma tryptophan, as well as the tryptophan/CAA ra- tio, are indicators for the availability of tryptophan to the brain (Fernstrom 1984) and, hence, for 5-HT synthesis in the brain (Moir and Eccleston 1968).

\section{Catecholamines}

Patients with autism show higher plasma norepinephrine (NE) concentrations than normal controls (Lake et al. 1977; Launay et al. 1987; Cook et al. 1990; Leventhal et al. 1990; Leboyer et al. 1992). This elevation was not observed by Minderaa et al. (1994). Urinary NE and 3-methoxy-4-hydroxyphenyl glycol (MHPG), the major NE metabolite, have been inconsistent and inconclusive (Young et al. 1978; Launay et al. 1987; Barthelemy et al. 1988; Martineau et al. 1992; Minderaa et al. 1994). A significantly higher homovanillylc acid (HVA)/MHPG ratio was found in the CSF of autistic subjects, suggesting an imbalance between the dopaminergic and noradrenergic systems (Gillberg and Svennerholm 1987). Findings concerning serum dopamine- $\beta$-hydroxylase have been inconsistent and inconclusive (Lake et al. 1977; Young et al. 1978; Garnier et al. 1986). However, to the best of our knowledge, no research on autism has demonstrated significant alterations in platelet $\left[{ }^{3} \mathrm{H}\right]$-rauwolscine binding characteristics. Serum tyrosine, the precursor of NE, was elevated in autistic patients with neurological signs but not in those without (Visconti et al. 1994). There is evidence that the synthesis of brain $\mathrm{NE}$ is determined, in part, by brain tyrosine concentrations, which are reflected in the serum by the molar ratio of tyrosine to the competing amino acids tryptophan, phenylalanine, leucine, isoleucine, and valine (for review see Moller 1986; Salter and Pogson 1987; Voog and Eriksson 1992).

The aims of the present study were to examine whether autism is accompanied by: 1) alterations in serotonergic functions such as lowered platelet $\left[{ }^{3} \mathrm{H}\right]$-paroxetine binding Bmax values, increased $\left[{ }^{3} \mathrm{H}\right]$-paroxetine binding $\mathrm{Kd}$ values, lower serum tryptophan concentrations and hyperserotonemia; and 2) alterations in noradrenergic functions such as decreases in platelet $\left[{ }^{3} \mathrm{H}\right]$-rauwolscine binding Bmax values, increased $\left[{ }^{3} \mathrm{H}\right]-$ rauwolscine binding $\mathrm{Kd}$ values and increased serum tyrosine and urinary catecholamine concentrations.

\section{SUBJECTS AND METHODS}

\section{Subjects}

Twenty-six male subjects, aged between 12 and $18 \mathrm{y}$, participated in the present study. All subjects passed the onset of puberty (Tanner-stage II-IV ) and were Caucasian. One subject in the pathology group had a mild mental retardation (I.Q. between 55 and 60), all other subjects showed a borderline intellectual func- 
tioning (I.Q. between 71 and 84) or normal intellectual functioning (I.Q. between 85 and 120). We did not perform a standard cognitive assessment prior to the blood/urine collections, since all subjects underwent neuropsychological and I.Q. tests during the years preceding the study. We employed the DSM-IV criteria to make the diagnosis of autism. The diagnosis was made on the basis of a consensus between, at least three clinicians (psychiatrists and psychologists), working with the autistic subjects in residential, semi-residential, or day-care centers. All subjects presented the three core autistic features without aggressive, impulsive, or hyperkinetic behaviours.

Normal volunteers and Autistic patients had a normal hematologic screening. Exclusion criteria for autistic patients and healthy volunteers were: subjects suffering from a neurological, inflammatory, endocrine, or clinically significant chronic disease; immunocompromized subjects; subjects receiving psychoactive drugs or drugs with known or potential interaction with serum amino-acids, 5-HT and $\alpha 2-\mathrm{ARs}$, and immune and endocrine functions; and subjects with an active seizure disorder. The autistic subjects underwent a genetic investigation during the years preceding the study and were excluded when positive for tuberous sclerosis, FRAXA, or other chromosomal disorders. All healthy volunteers had a negative past, present, or family history for psychiatric disorders. None was a regular drinker and none had ever been taking psychotropic drugs. All were free of any medications and substance abuse for at least one month. This was checked by a drug-screening test of the urine.

\section{Methods}

All subjects received a VMA-free diet during the 24hours preceding the onset of blood-and urine collections. Subjects were kept at rest during the urine collections. Urine was kept at $-3^{\circ} \mathrm{C}$ in dark bottles. After completing the collection, urine samples were frozen at $-75^{\circ} \mathrm{C}$ until thawed for assay. One day after the urine collection, blood was drawn at 7:45 a.m. ( $\pm 15 \mathrm{~min}$ ) after an overnight fast for the assays of serum amino acids, 5-HT and platelet $\left[{ }^{3} \mathrm{H}\right]$-paroxetine and $\left[{ }^{3} \mathrm{H}\right]$-rauwolscine binding assays. In order to control for possible seasonal effects in serotonergic measurements ( $\mathrm{D}^{\prime}$ Hondt et al. 1996; Maes et al. 1995), all samples were collected over two days in the same week (last week of September 1997). All assays were done blind to the subject's status. Serum and plasma samples for the various assays were kept at $-75^{\circ} \mathrm{C}$ until thawed for assay.

In order to minimize the analytical variability, all blood specimens for the assays of the above parameters in autistic patients and healthy volunteers were assayed in a single run with a single lot number of reagents and consumables employed by a single operator (Maes et al.
1994). HPLC (BIORAD; Eke, Nazareth, Belgium) was employed to measure tryptophan, tyrosine, and the amino acids known to compete with the same cerebral transport system, i.e., valine, leucine, phenylalanine, and isoleucine (Turnell and Cooper 1982; Maes et al. 1996), 5-HT, 5-HIAA, and the catecholamines. The intra-assay $\mathrm{CV}$ values obtained in our laboratory were: tryptophan $3.3 \%$; tyrosine $3.8 \%$; valine $3.0 \%$; phenylalanine $3.2 \%$; isoleucine $3.4 \%$; and leucine $3.7 \%$. The tryptophan/valine + leucine + isoleucine + tyrosine + phenylalanine (CAA1) and the tyrosine/valine + leucine + isoleucine + tryptophan + phenylalanine (CAA2) ratios were computed and multiplied by 100 . The intra-assay CV value for $5-\mathrm{HT}$ was $6.0 \%$ and for the all assays in urine $<10 \%$.

Platelet $\left[{ }^{3} \mathrm{H}\right]$-paroxetine and $\left[{ }^{3} \mathrm{H}\right]$-rauwolscine $\mathrm{Kd}$ and Bmax values were determined as described previously (Maes et al. 1998, 1999). Two $9 \mathrm{ml}$ blood samples were collected and transferred in siliconized tubes containing K-EDTA as anticoagulant. Within $60 \mathrm{~min}$, platelet-rich plasma was prepared by low speed centrifugation for $10 \mathrm{~min}$ at $1500 \mathrm{rpm}(750 \mathrm{~g})$. Platelets were isolated in four centrifugation runs, pooled, counted, and washed in $8 \mathrm{ml}$ buffer A (TRIS $50 \mathrm{mM}, \mathrm{NaCl} 150$ $\mathrm{mM}$, EDTA $20 \mathrm{mM}, \mathrm{pH}$ 7.5). Platelets were counted by means of a Coulter STKS fully automated total blood cell counter. The final pellet was disrupted with and frozen in $2 \mathrm{ml}$ ice-cold buffer B (TRIS $5 \mathrm{mM}$, EDTA 5 $\mathrm{mM}, \mathrm{pH}$ 7.5). Samples were frozen at $-80^{\circ} \mathrm{C}$ until thawed for determination of binding assays. After thawing and adding $6 \mathrm{ml}$ buffer $\mathrm{B}$, the platelet membranes were centrifuged twice in a Beckman PG centrifuge at $18000 \mathrm{rpm}$ (39000g) and twice disrupted using an ultra-turrax homogenizer. The final membrane pellet was suspended in $0.8 \mathrm{ml}$ buffer $\mathrm{C}$ (glycylglycine $25 \mathrm{mM}, \mathrm{pH} 7.6$ ), resulting in a final concentration of $4000 \times 10 \mathrm{E} 6 / \mathrm{mL}$.

For the $\left[{ }^{3} \mathrm{H}\right]$-paroxetine binding assays, incubation mixtures consisted of $50 \mu$ l platelet membrane suspension, $400 \mu$ l Buffer D (Tris $\mathrm{HCl} 50 \mathrm{mM}, \mathrm{NaCl} 120 \mathrm{mM}$, $\mathrm{KCl} 5 \mathrm{mM}), 25 \mu \mathrm{l}\left[{ }^{3} \mathrm{H}\right]$-paroxetine at final concentrations between 0.02 and $0.8 \mathrm{nM}$, and $25 \mu \mathrm{l}$ ethanol $10 \%$ or $25 \mu \mathrm{l}$ imipramine (diluted in ethanol $10 \%$, in a final concentration of $10 \mu \mathrm{M}$ incubation mixture and a $1000 \mathrm{X}$ excess of $\left[{ }^{3} \mathrm{H}\right]$-paroxetine. Radio-activity was counted after 12 $\mathrm{h}$ of incubation in a Packard 460 scintillation counter. Specific binding (as a percentage of total binding) was $73 \% \pm 5 \%$. After incubation for $120 \mathrm{~min}$ at $25^{\circ} \mathrm{C}$, samples were rapidly filtered through Whatman GF/B glass fibre filters under vacuum and rinsed twice with 4 $\mathrm{ml}$ ice-cold buffer. We used a 40-well filtration manifold. Filters were placed in vials with $2 \mathrm{ml}$ scintillationfluid (Packard Ultima-Gold).

For the $\left[{ }^{3} \mathrm{H}\right]$-rauwolscine binding assays, the incubation mixtures consisted of $50 \mu$ l platelet suspension, 50 $\mu l^{3}[\mathrm{H}]$-rauwolscine at final concentrations between 0.1 and $4.0 \mathrm{nM}$, and $400 \mu \mathrm{l}$ buffer C. Specific binding was 
defined as radioactivity displaced by $10 \mathrm{mM}$ Idazoxan. Specific binding was $80-90 \%$. The solution was incubated for $60 \mathrm{~min}$ at $25^{\circ} \mathrm{C}$. The samples were rapidly filtered through Whatman GF/B glass fiber filters under vacuum and rinsed twice with $4 \mathrm{ml}$ ice-cold buffer $\mathrm{E}$ (TRIS $50 \mathrm{mM}$, pH 7.4). Filters were placed in vials with $2 \mathrm{ml}$ scintillation-cocktail (Packard Ultima-Gold). Radio-activity was counted after $16 \mathrm{~h}$ in a Packard 460 scintillation counter. Data were analyzed using computerized curve fitting, i.e., LIGAND. Bmax and $\mathrm{Kd}$ values were derived from the calculated curves. Bmax was expressed as fmoles/10E6 platelets. Blood specimens for the assay of platelet $\left[{ }^{3} \mathrm{H}\right]$-paroxetine and $\left[{ }^{3} \mathrm{H}\right]$-rauwolscine binding characteristics were carried out with a single lot number of reagents and consumables employed by a single operator. In order to minimize the inter-assay analytical variability, we analyzed all samples for one given parameter in the same run, on one and the same day.

\section{Statistics}

The independence between classification systems was checked with the analysis of contingence tables ( $\chi^{2}$ test). Group mean differences were checked by means of analysis of variance (ANOVA) or analysis of covariance (ANCOVA). The latter was employed to adjust for possible age effects by entering age as a covariate in the regression analyses. Relationships between variables were assessed with Pearson's product-moment correlation coefficients and through regression analyses. Normality of distribution was assessed with the Kolmogorov-Smirnov test. Transformations were used to reach normality of distribution or to adjust for heterogeneity of variance between study groups.

Table 1. Measurements of Serum Amino Acids and the Availability of Tryptophan and Tyrosine to the Brain in Normal Controls and Autistic Patients

\begin{tabular}{lcccl}
\hline Variables & Controls & Autism & F & $\boldsymbol{p}$ \\
\hline Tryptophan & $70(11)$ & $58(11)$ & 6.1 & .02 \\
Tyrosine & $64(11)$ & $61(10)$ & 0.9 & .6 \\
Valine & $258(24)$ & $235(32)$ & 4.0 & .054 \\
Phenylalanine & $107(167)$ & $52(7)$ & 7.7 & .01 \\
Isoleucine & $75(9)$ & $66(14)$ & 6.1 & .02 \\
Leucine & $146(12)$ & $129(21)$ & 6.1 & .02 \\
CAA1 & $604(52)$ & $543(74)$ & 5.8 & .02 \\
Tryptophan/ & & & & \\
$\quad$ CAA1 $\times 100$ & $11.52(1.52)$ & $10.77(1.87)$ & 1.3 & .3 \\
CAA2 & $609(51)$ & $541(75)$ & 7.4 & .01 \\
Tyrosine/ & & & & \\
$\quad$ CAA2 $\times 100$ & $10.58(1.46)$ & $11.31(1.77)$ & 1.33 & .3 \\
\hline
\end{tabular}

All results are shown as mean (SD) and in $10^{-6} \mathrm{M} / \mathrm{L}$. All results of ANOVAs $(\mathrm{df}=1 / 24)$.

CAA1: sum of tyrosine, phenylalanine, valine, leucine, and isoleucine.

CAA2: sum of tryptophan, phenylalanine, valine, leucine, and isoleucine.

\section{RESULTS}

\section{Demographic Data}

There were no significant differences in age $(\mathrm{F}=0.89$, $\mathrm{df}=1 / 24, p=.6$ ) between patients with autism (mean age $=14.5 \pm 1.8$ years) and healthy volunteers (mean age $=15.1 \pm 1.5$ years). There were no significant correlations between age and tyrosine $(\mathrm{r}=0.27, p=.2)$, tyrosine/CAA2 ratio $(\mathrm{r}=0.06, p=.8),\left[{ }^{3} \mathrm{H}\right]$-paroxetine binding $\operatorname{Bmax}(\mathrm{r}=0.13, p=.5)$, or $\mathrm{Kd}(\mathrm{r}=-0.34, p=$ .08) values; $\left[{ }^{3} \mathrm{H}\right]$-rauwolscine binding $B \max (\mathrm{r}=-0.18$, $p=.6)$, or $\mathrm{Kd}(\mathrm{r}=0.18, p=.6)$ values; 5 -HT in whole blood $(r=0.25, p=.2)$, serum $(r=0.15, p=.5)$, and platelet rich plasma $(\mathrm{r}=0.01, p=.9)$; and NE in 24-hour urine $(\mathrm{r}=-0.16, p=.5)$. There was a significant and positive correlation between age and serum tryptophan $(\mathrm{r}=0.48, p=.01)$ and 5-HIAA in 24-hour urine $(\mathrm{r}=$ $0.50, p=.008)$. There was a trend toward a positive correlation between age and the tryptophan/CAA1 ratio $(\mathrm{r}=0.38, p=.054)$ (all results of intra-class correlations, pooled over the study groups of normal controls and autistic patients). In order to adjust for possible effects of age when examining intergroup differences, we employed ANCOVAs in the case of serum tryptophan, tryptophan/CAA1 ratio, and 5-HIAA.

\section{Biological Markers and Autism}

Table 1 shows that there were significant differences in serum tryptophan, phenylalanine, leucine, isoleucine, CAA1, and CAA2, as well as a trend toward a significant difference in serum valine between autistic patients and healthy volunteers. Covarying for age did not change the tryptophan results $(\mathrm{F}=6.1, \mathrm{df}=1 / 23$, $p=.02$ ). The tryptophan/CAA1 ratio, serum tyrosine, and the tyrosine/CAA2 ratio were not significantly different between autistic subjects and normal volunteers. ANCOVA with age as covariate did not disclose significant differences in the tryptophan/CAA1 ratio between the study groups $(\mathrm{F}=0.7, \mathrm{df}=1 / 23, p=.6)$.

Table 2 shows the measurements of the serotonergic markers in the autistic and normal children. The $\left[{ }^{3} \mathrm{H}\right]-$ paroxetine binding $\mathrm{Kd}$ values were significantly higher in the autistic patients than in healthy volunteers. There were no significant differences in $\left[{ }^{3} \mathrm{H}\right]$-paroxetine binding Bmax values between autistic patients and healthy volunteers. There were no significant differences in the 5-HT values in whole blood, serum, platelet-rich plasma, and in the 5-HIAA values in 24-hr urine between autistic patients and healthy volunteers. ANCOVA with age as covariate did not disclose significant differences in 24-hour urinary 5-HIAA between both study groups $(\mathrm{F}=1.1, \mathrm{df}=1 / 23, p=.3)$. There were no significant intercorrelations between the tryptophan data, 5-HT values and $\left[{ }^{3} \mathrm{H}\right]$-paroxetine binding characteristics (tested at the $p=.05$ level). 
Table 2. Serotonergic Markers in Autism; $\left[{ }^{3} \mathrm{H}\right]$-paroxetine Binding Bmax and Kd Values, Serotonin (5-HT) in Blood, and Urinary 5-hydroxyindoleacetic Acid in Autistic Patients and Normal Volunteers

\begin{tabular}{lcccl}
\hline Variables & Controls & Autism & F & $p$ \\
\hline Bmax $\left[{ }^{3} \mathrm{H}\right]$-paroxetine $\left(\mathrm{fmoles} / 10^{6}\right.$ platelets) & $0.29(0.12)$ & $0.27(0.12)$ & 0.09 & .7 \\
Kd $\left[{ }^{3} \mathrm{H}\right]$-paroxetine $(\mathrm{nM})$ & $0.040(0.026)$ & $0.099(0.010)$ & 4.25 & .04 \\
5-HT in whole blood $(\mathrm{ng} / \mathrm{mL})$ & $206(68)$ & $223(39)$ & 0.4 & .5 \\
5-HT in serum $(\mathrm{ng} / \mathrm{mL})$ & $116(48)$ & $108(39)$ & 0.2 & .6 \\
5-HT in platelet rich plasma $(\mathrm{ng} / \mathrm{mL})$ & $76(44)$ & $95(46)$ & 1.1 & .3 \\
5-HIAA in 24 hr urine $(\mu \mathrm{g} / 24 \mathrm{hr})$ & $3.72(1.14)$ & $3.98(1.91)$ & 0.2 & .7 \\
\hline
\end{tabular}

All results are shown as mean $(\mathrm{SD})$. All results of ANOVAs $(\mathrm{df}=1 / 24)$.

Table 3 shows the measurements of the catecholaminergic variables. The $\left[{ }^{3} \mathrm{H}\right]$-rauwolscine binding Bmax and $\mathrm{Kd}$ values were not significantly different between autistic patients and normal volunteers. There were no significant differences in the NE, adrenaline, and dopamine values in the 24-hour urine between autistic patients and healthy volunteers.

\section{DISCUSSION}

The present study showed that the affinity of platelet $\left[{ }^{3} \mathrm{H}\right]$-paroxetine binding sites is significantly decreased in post-pubertal, caucasian, autistic male subjects with an I.Q. $>55$. These findings may suggest a disorder in the platelet 5-HT transporter system in autism. A question, however, is whether peripheral findings are relevant for the central serotonergic activity. Blood platelets are able to take up, store, and release 5-HT via mechanisms that are very similar to those of central 5-HT neurons (Sneddon 1973; Stahl 1977). $\left[{ }^{3} \mathrm{H}\right]$-paroxetine binds with high affinity to a specific population of binding sites located on platelets and neuronal membranes associated with 5-HT uptake mechanisms (Mellerup et al. 1983; Habert et al. 1985; Cheetham et al. 1993).

A previous study showed that the cloned 5-HT transporter on human platelets is identical to the 5-HT transporter in human brain (Lesch et al. 1993). The findings of Fichtner et al. (1994), who found a positive response to fluoxetine pharmacotherapy in patients with post-traumatic stress disorder with lower platelet $\left[{ }^{3} \mathrm{H}\right]-$ paroxetine Bmax values, suggest that findings on platelet $\left[{ }^{3} \mathrm{H}\right]$-paroxetine binding may be relevant for central serotonergic activity. Interestingly, there is some preliminary evidence of linkage and association between the 5-HT transporter gene and autistic behavior (Cook et al. 1997; Klauck et al. 1997). Concerning those serotonergic genetic factors, there are some discrepancies between Cook et al. (1997) and Klauck et al. (1997) who found an association to the long rather than the short allele of the 5-HT transporter gene in autistic subjects. Clarification of the role of genetic variants of the 5-HT transporter in the etiology of autism is needed by means of further studies with larger study groups.

The above findings may suggest that Autism is accompanied by defects in the peripheral and perhaps central 5-HT transporter system. Weizman et al. (1987), on the other hand, were unable to find any significant differences in platelet imipramine binding characteristics in autistic patients. The findings that peripheral 5-HT and 5-HIAA values were normal and that there were no significant correlations between those peripheral markers and the $\left[{ }^{3} \mathrm{H}\right]$-paroxetine $\mathrm{Kd}$ values suggest that the peripheral serotonergic turnover is probably not involved in the changes in the 5-HT transporter system in post-pubertal, caucasian autistic male subjects with an I.Q. $>55$.

In the present study, we found significant lower serum concentrations of total tryptophan in the group of autistic children, although the tryptophan/CAA ratio was not significantly lowered in the autistic subjects. Tryptophan circulates in the blood with a minor frac-

Table 3. Measurements of Catecholaminergic Markers in Autism, i.e., the Platelet $\left[{ }^{3} \mathrm{H}\right]$-rauwolscine Binding Bmax and Kd Values and $24 \mathrm{hr}$ Urinary Excretion of Noradrenaline (NE), Adrenaline (E), and Dopamine (Dop)

\begin{tabular}{lcccc}
\hline Variables & Controls & Autism & F & $p$ \\
\hline$\left[{ }^{3} \mathrm{H}\right]-$ rauwolscine Bmax (fmoles $/ 10^{6}$ platelets) & $0.098(0.040)$ & $0.098(0.048)$ & 0.00 & .9 \\
$\left.{ }^{3} \mathrm{H}\right]-\mathrm{rauwolscine} \mathrm{Kd} \mathrm{(nM)}$ & $0.35(0.57)$ & $0.31(0.32)$ & 0.07 & .8 \\
$\mathrm{NE}(\mu \mathrm{g} / 24 \mathrm{hr})$ & $36(9)$ & $45(21)$ & 1.9 & .2 \\
$\mathrm{E}(\mu \mathrm{g} / 24 \mathrm{hr})$ & $9.2(5.4)$ & $9.5(4.4)$ & 0.02 & .9 \\
$\mathrm{Dop}(\mu \mathrm{g} / 24 \mathrm{hr})$ & $306(100)$ & $331(110)$ & 0.4 & .6 \\
\hline
\end{tabular}

All results are shown as mean $(\mathrm{SD})$. All results of ANOVAs $(\mathrm{df}=1 / 24)$. 
tion free, whereas $70-90 \%$ of this amino acid is loosely bound to serum albumin (for review, see Maes et al. 1996). It is thought that the blood-brain-barrier transport site of tryptophan and its CAA strips off albumin as they pass through the brain capillaries and, consequently, that the availability of tryptophan to the brain depends on serum concentrations of free and total tryptophan, as well as on the concentrations of albumin and the CAA (Pardridge 1979; Yuwiler et al. 1977). The measurement of free, in addition to, total tryptophan as a measure of the tryptophan availability to the brain would have been more informative. In addition, since the tryptophan/CAA ratio is not decreased, it remains unclear whether the availability of tryptophan to the brain is decreased in autism. The lack of any changes in the tryptophan/CAA ratio in autism is explained by the significant decreases in the sum of CAA in autism, which, in turn, is attributable to lowered serum concentrations of phenylalanine, leucine, isoleucine, and valine.

These findings may indicate a more generalized disorder in protein metabolism in autism. To further investigate this possibility, we planned to examine markers of protein metabolism, such as total serum protein, protein electrophoresis, and serum proteins, including albumin and retinol binding protein. In accordance with previous hypotheses, the results of our study suggest that serotonergic mechanisms may play a role in the pathophysiology of autism. As described in the Introduction, evidence that the serotonergic system is involved in the pathophysiology of autism comes from pharmacological studies with SSRIs (McDougle et al. 1996a), behavioral research, such as results of tryptophan depletion techniques (McDougle et al. 1996b), molecular biology (Cook and Leventhal 1996; Cook et al. 1997) and brain imaging (Chugani et al. 1997, 1999).

In our study group consisting of post-pubertal, caucasian, autistic, male subjects with an I.Q. $>55$, we could not find a hyperserotonemia, which was reported to occur in autism (see Introduction). The smaller number of subjects $(n=13)$ in our study could have lowered the power to detect any differences in 5-HT between both study groups. For example, we found a $25 \%$ elevation in platelet-rich plasma 5 -HT but only $8.2 \%$ in whole blood in the autistic group as compared with normal controls. Nevertheless, previous studies showed that whole blood 5-HT is not significantly different between post-pubertal, caucasian males with autism and normal controls and that hyperserotonemia may be confined to prepubertal children with autism (McBride et al. 1998).

Another major finding of this study is that serum tryptophan and 5-HIAA in 24-hour urine are significantly and positively correlated with age in both autistic subjects and normal controls. These findings may indicate that the serotonergic system undergoes significant changes during the lifespan, e.g., from the post-puber- tal period to adulthood (Riddle et al. 1986; McBride et al. 1990). Recent findings suggest that humans undergo a period of high brain 5-HT synthesis capacity during childhood, and that this developmental process is disrupted in autistic children (Chugani et al. 1999).

Given the fact that all but one of the autistic subjects belong to the high functioning group, we cannot exclude whether the findings are specific for the entire autistic population or might be confined to the higher $30 \%$ of the overall population of autistic subjects. It remains unclear whether (or to what extent) disturbances in the serotonergic system may contribute to the overall phenotype of autism or only to the degree of severity of autism and/or the presence and severity of associated features. Also, from a genetic point of view, recent evidence shows that the disorder is genetically heterogeneous (Szatmari 1999). Higher functioning individuals with autism may have another genetic background than lower functioning ones.

The results of the present study suggest that there are no significant alterations in the peripheral turnover of catecholamines in autism. The maximum number of binding sites (B max) and the affinity of $\left[{ }^{3} \mathrm{H}\right]$-rauwolscine binding to platelets was not significantly altered in patients with autism. The technique employed here to measure $\alpha 2$-AR characteristics is meaningful and adequate since: (i) employing the same technique, i.e., with $\left[{ }^{3} \mathrm{H}\right]$-rauwolscine as ligand and idozoxan for the specific binding, we were able to find significant alterations in $\left[{ }^{3} \mathrm{H}\right]$-rauwolscine binding characteristics in major depression and post-traumatic stress disorder (Maes et al. 1998, 1999); and (ii) inhibition of $\left[{ }^{3} \mathrm{H}\right]$-dihydroergocryptine binding by antagonists showed that there was a single population of antagonist binding sites with the pharmacological characteristics of $\alpha 2-$ ARs, whereas inhibition by agonists showed two sites with different affinities (Hoffman et al. 1979).

Adrenoceptors of the $\alpha 2 \mathrm{~A}$ subtype are expressed on platelets and presynaptically on noradrenergic neurons (Hieble et al.1995; Limberger et al. 1995). Since platelet $\alpha 2$-ARs have very similar pharmacologic and kinetic properties as those in the brain, platelet $\alpha 2$-ARs may be an adequate model for brain $\alpha 2$-ARs (Stahl 1985). Furthermore, the lack of any changes in serum tyrosine, the NE-precursor, and in the urinary excretion of catecholamines suggest that there are no marked abnormalities in baseline catecholaminergic turnover in post-pubertal, caucasian autistic male patients with an I.Q. $>55$. As reviewed in the Introduction, contradictory results were obtained on the catecholaminergic turnover in autism (Launay et al. 1987; Martineau et al. 1992; Minderaa et al. 1994; Young et al.1978, 1981; Barthelemy et al. 1988; Gillberg and Svennerholm 1987).

As described above, there were many inconsistent or inconclusive data concerning peripheral markers of monoamine metabolism in the autistic disorder. This is 
often due to differences in the characteristics of the study groups, e.g., with respect to age, sex, race, I.Q., and pubertal status, or differences in the methods used to measure the variables. In the present study, we have controlled for or otherwise may dismiss the intervening effects of variables such as age (all subjects were between 12 and 18 years old), sex (all males), race (all Caucasians), I.Q. (no mental retardation), drug state of the patients (all subjects were drug free), dietary factors (all were on a VMA low diet), seasonal rhythms (all samples were collected in the same week), or autistic symptomatology (all patients were without aggressive, impulsive or hyperkinetic behaviours). Moreover, we minimized the analytical variability in the biological variables since all assays were run at the same time using the same chemicals. Limitations of the present study, however, are the smaller number of autistic subjects and controls $(n=13)$ and the lack of inclusion of autistic patients with specific psychopathological dimensions, e.g., aggressive and obsessive behaviors. Another possible limitation is that we did not use a structured interview to make the diagnosis of autism, although our diagnosis was based on a consensus between several clinicians. Future research should focus on: (i) further genetic studies of the 5-HT transporter in autistic subjects and their parents; (ii) brain imaging studies evaluating the central serotonergic system; and (iii) functional tests of the central serotonergic function by performing neuroendocrine challenge tests with specific serotonergic agonists stimulating 5-HT1A, 5-HT2A, 5-HT2C, or other 5-HT receptors.

\section{ACKNOWLEDGMENTS}

This research was supported in part by the Clinical Research Center for Mental Health (CRC-MH) and the Janssen Research Foundation, Beerse, Belgium. We would like to thank W. Gommeren, R.T., and Prof. Dr. J. Leysen of the Janssen Research foundation, 'De Speling' (a Treatment Centre For Autistic Youngsters, Booischot, Belgium), the L.S.A. (an association of parents of children with autism in Limburg, Belgium), and Mrs. M. Elseviers, Department of Nephrology, University of Antwerp, Wilrijk, Belgium.

\section{REFERENCES}

American Psychiatric Association (1987): Diagnostic and Statistical Manual of Mental Disorders, 3rd ed. Washington, DC, American Psychiatric Association

American Psychiatric Association (1994): Diagnostic and Statistical Manual of Mental Disorders, 4th ed. Washington, DC, American Psychiatric Association

Barthelemy C, Bruneau N, Cottet-Eymard JM, DomenechJouve J, Garreau B, Lelord G, Muh JP, Peyrin L (1988): Urinary free and conjugated catecholamine and metabolites in autistic children. J Autism Dev Disord 18:585-591
Cheetham SC, Viggers JA, Slater NA, Heal DJ, Buckett WR (1993): [ $\left.{ }^{3} \mathrm{H}\right]$ Paroxetine binding in rat frontal cortex strongly correlates with $\left[{ }^{3} \mathrm{H}\right]-5-\mathrm{HT}$ uptake: Effect of administration of various antidepressant treatments. Neuropharmacology 32:737-743

Chugani DC, Muzik O, Rothermel R, Behen M, Chakraborty P, Mangner T, da Silva EA, Chugani HT (1997): Altered serotonin synthesis in the dentatothalamocortical pathway in autistic boys. Ann Neurol 42:666-669

Chugani DC, Muzik O, Behen M, Rothermel R, Janisse JJ, Lee J, Chugani HT (1999): Developmental changes in brain serotonin synthesis capacity in autistic and nonautistic children. Ann Neurol 45:287-295

Cook EH, Leventhal BL, Heller W, Metz J, Wainwright M, Freedman DX (1990): Autistic children and their firstdegree relatives : Relationships between serotonin and norepinephrine levels and intelligence. J Neuropsych Clin Neurosci 2:268-274

Cook E, Arora R, Anderson G, Berry-Kravis E, Yan S-Y, Yeoh H, Sklena P, Charak D, Leventhal B (1993): Platelet serotonin studies in hyperserotonemic relatives of children with autistic disorder. Life Sci 52:2005-2015

Cook E, Leventhal BL (1996): The serotonin system in autism. Curr Opin Pediatr 8:348-354

Cook EH, Chourchesne R, Lord C, Cox NJ, Yan S, Lincoln A, Haas R, Courchesne E, Leventhal BL (1997): Evidence of Linkage between the serotonin transporter and autistic disorder. Mol Psychiatry 2:247-250

D’Eufemia P, Finocchiaro R, Celli M, Viozzi L, Monteleone D, Giardini O (1995): Low serum tryptophan to large amino acids ratio in idiopathic infantile autism. Biomed Pharmacother 49:288-292

D'Hondt P, Maes M, Leysen J, Gommeren W, Scharpe S, Cosyns P (1996): Seasonal variation in paroxetine binding to platelets in normal volunteers: Relationships to climatic factors. Neuropsychopharmacology 5:187-198

Fernstrom JD (1984): Tryptophan availability and serotonin synthesis in rat brain: Effects of experimental diabetes. In Schlossberger HG, Kochen W, Linzen B, Steinhart H (eds), Progress in Tryptophan and Serotonin Research. New York, NY, Walter de Gruyter, pp 161-172

Fichtner CG, Arora RC, O'Connor FL, Crayton JW (1994): Platelet paroxetine binding and fluoxetine pharmacotherapy in posttraumatic stress disorder: Preliminary observations on a possible predictor of clinical treatment response. Life Sci 54:39-44

Garnier C, Comoy E, Barthelemy C, Leddet I, Garreau B, Muh JP, Lelord G (1986): Dopamine-betahyroxylase and homovanillic acid in autistic children. J Autism Dev Disord 16:23-29

Gillberg C, Svennerholm L (1987): CSF monoamines in autistic syndromes and other pervasive developmental disorders of early childhood. Br J Psychiatry 151:89-94

Habert E, Graham D, Tahraoui L, Claustre Y, Langer S (1985): Characterization of [3H]-paroxetine binding to rat cortical membranes. Eur J Pharmacol 118:107-114

Hamberger A, Gillberg C, Palm A, Hagberg B (1982): Elevated CSF glutamate in Rett syndrome. Neuropediatrics 23:212-213

Hanley HG, Stahl SM, Freeman DX (1977): Hyperserotone- 
mia and amine metabolites in autistic and retarded children. Arch Gen Psychiatry 34:521-531

Hieble JP, Bondinell WE, Ruffolo RR (1995): $\alpha$ - and $\beta$-adrenoceptors: From the gene to the clinic. I. Molecular biology and adrenoceptor classification. J Med Chem 38: 3415-3444

Hoffman BB, DeLean A, Wood CL, Schocken DD, Lefkowitz RJ (1979): Alpha-adrenergic subtypes: quantitative assessment by ligand binding. Life Sci 24:1739-1746

Hoshino Y, Yamamoto T, Kaneko M, Kumashiro H (1986): Plasma free tryptophan concentration in autistic children. Brain Dev 8:424-427

Jackson MJ, Garrod PJ(1978): Plasma zinc, copper and amino acid levels in the blood of autistic children. J Autism Dev Disord 8:203-208

Johnson RJ, Wiersema V, Kraft IA (1974): Hair amino acids in childhood autism. J Autism Child Schizophr 4:187-188

Klauck SM, Poustka F, Benner A, Lesch KP, Poustka A (1997): Serotonin transporter (5-HTT) gene variants associated with autism? Human Mol Genet 6(13):2233-2238

Lake CR, Ziegler MG, Murphy DL (1977): Increased norepinephrine levels and decreased dopamine-beta-hydroxylase activity and primary autism. Arch Gen Psychiatry 34:553-556

Launay JM, Bursztejn C, Ferrari P, Dreux C, Braconnier A, Zarifian E, Lancrenon S, Fermanian J(1987): Catecholamine metabolism in infantile autism: A controlled study of 22 autistic children. J Autism Dev Disord 17:333-347

Leboyer M, Bouvard MP, Launay JM (1992): A double-blind study of naltrexone in infantile autism [Brief report]. J Autism Dev Disord 22:309-319

Lesch KP, Wolozin BL, Murphy DL, Reiderer P (1993): Primary structure of the human platelet serotonin uptake site: Identity with the brain serotonin transporter. J Neurochem 60:2319-2322

Leventhal BL, Cook EH Jr, Morford M, Ravitz A, Freedman DX (1990): Relationships of whole blood serotonin and plasma norepinephrine within families. J Autism Dev Disord 20:499-511

Limberger N, Funk L, Trendelenburg AU, Starke K (1995): Subclassification of presynaptic a2-adrenoceptors: a2autoreceptors in rabbit atria and kidney. NaunynSchmiedeberg's Arch Pharmacol 352:31-42

Maes M, Scharpe S, Cosyns P, Neels H, Stevens W, Bridts C, Thompson P, DeClerck L, D'Hondt P, DeMeyer F, Ranjan R, Meltzer HY, Peeters D, Wouters A, Cooreman W (1994): Components of biological variation in serum activity of dipeptidyl peptidase IV and prolyl endopeptidase in normal man. Clin Chem 40:1686-1691

Maes M, Scharpe S, Cosyns P, Neels H, Stevens W, Bridts C, Thompson P, DeClerck L, D'Hondt P, DeMeyer F, Ranjan R, Meltzer HY, Peeters D, Wouters A, Cooreman W (1995): Components of biological variation, including seasonality in plasma L-tryptophan and competing amino-acids in man: Relationships to serum total protein, climatic variables and violent suicide occurrence. Arch Gen Psychiatry 52:937-945

Maes M, Wauters A, Verkerk R, Neels H, van Gastel A, Cosyns P, Scharpe S, Desnyder R (1996): Lower L-tryptophan availability in depression: A marker of a more generalized disorder in protein metabolism. Neuropsychopharmacology 15:243-251

Maes M, van Gastel A, Delmeire L, Gommeren W, Leysen J (1998): Decreased $\alpha 2$ receptor binding sites on platelets of depressed patients: Effects of tricyclic antidepressants and SSRIs. Biol Psychiatry 45:278-284

Maes M, Lin A, Verkerk R, Delmeire L, van Gastel A, Gommeren W, Leysen J, Scharpe S (1999): Serotonergic and noradrenergic markers of posttraumatic stress disorder: Lower affinity of platelet paroxetine and alpha-2 binding sites and increased plasma tyrosine availability to the brain. Neuropsychopharmacology 20:188-197

Martineau J, Barthelemy C, Jouve J, Muh JP, Lelord G (1992): Monoamines (serotonin and catecholamines) and their derivatives in infantile autism: Age-related changes and drug effects. Dev Med Child Neurol 34:593-603

McBride PA, Tierney H, DeMeo M, Chen JS, Mann JJ (1990): Effects of age and gender on CNS serotonergic responsivity in normal adults. Biol Psychiatry 27:1143-1155

McBride PA, Anderson GM, Hertzig ME, Snow ME, Thompson SM, Khait VD, Shapiro T, Cohen DJ (1998): Effects of diagnosis, race, and puberty on platelet serotonin levels in autism and mental retardation. J Am Acad Child Adolesc Psychiatry 37:767-776

McDougle CJ, Naylor ST, Cohen DJ, Aghajanian GK, Heninger GR, Price LH (1996a): Effects of tryptophan depletion in drug-free adults with autistic disorder. Arch Gen Psychiatry 53:993-1000

McDougle CJ, Naylor ST, Cohen DJ, Volkmar FR, Heninger GR, Price LH (1996b): A double-blind, placebo-controlled study of fluvoxamine in adults with autistic disorder. Arch Gen Psychiatry 53:1001-1008

Mellerup ET, Plenge P, Engelstoft M (1983): High affinity binding of $\left[{ }^{3} \mathrm{H}\right]$-paroxetine and $\left[{ }^{3} \mathrm{H}\right]$-imipramine to human platelet membranes. Eur J Pharmacol 96:303-309

Minderaa R, Anderson GM, Volkmar FR,Harcherick D, Akkerhuis GW, Cohen DI (1989): Whole blood serotonin and tryptophan in autism: Temporal stability and effects of medication. J Autism Dev Disord 19:129-136

Minderaa R, Anderson GM, Volkmar FR, Akkerhuis GW, Cohen DI (1994): Noradrenergic and adrenergic functioning in autism. Biol Psychiatry 36:237-241

Moir ATB, Eccleston D (1968): The effect of precursor loading in the cerebral metabolism of 5-hydroxyindoles. J Neurochem 15:1093-1108

Moller SE (1986): Plasma neutral amino acids and food preferences: Possible implications in normals and depressives. Biblthca Nutr Dieta 38:149-153

Pardridge WM (1979): Tryptophan transport through the blood-brain barrier: In vivo measurement of free and albumin-bound amino acid. Life Sci 25:1519-1528

Perry TL, Hansen S, Christie RG (1978): Amino compounds and organic acids in CSF, plasma and urine of autistic children. Biol Psychiatry 13:575-586

Riddle MA, Anderson GM, McIntosh S, Harcherick DF, Shaywitz BA, Cohen DJ (1986): Cerebrospinal fluid monoamine precursor and metabolite levels in children treated for leukemia: Age and sex effects and individual variability. Biol Psychiatry 21:69-83 
Salter M, Pogson CI (1987): The importance of the liver as a regulator of amino acid supply to the brain. In Huether G (ed), Amino Acid Availability and Brain Function in Health and Disease. Berlin, Germany, Springer-Verlag, pp 21-28

Schain RJ, Freedman DX (1996): Studies on 5-hydroxyindole metabolism in autistic and other mentally retarded children. J Pediatrics 58:315-320

Sneddon JM (1973): Blood platelets as a model for monoamine-containing neurons. Progr Neurobiol 1:151-198

Stahl SM (1977): The human platelet: A diagnostic and research tool for the study of biogenic amines in psychiatry and neurologic disorders. Arch Gen Psychiatry 34:509-516

Stahl SM (1985): Peripheral models for the study of neurotransmitter receptors in man. Psychopharmacol Bull 21:663-671

Szatmari P (1999): Heterogeneity and the genetics of autism. J Psychiatry Neurosci 24:159-165

Turnell D, Cooper J (1982): Rapid assay for amino acids in serum or urine by precolumn derivatisation and reversed-phase liquid chromatography. Clin Chem 28:527-531

Voog L, Eriksson T (1992): Relationship between plasma and brain large neutral amino acids in rats fed diets with different compositions at different times of the day. J Neurochem 59:1868-1874

Visconti P, Piazzi S, Posar A, Santi A, Pipitone E, Rossi PG (1994): Amino acids and infantile autism. Dev Brain Dysf 7:86-92

Weizman A, Gonen N, Tyano S, Szekely GA, Rehavi M (1987): Platelet [3H]imipramine binding in autism and schizophrenia. Psychopharmacology 91:101-103

Winsberg BG, Sverd J, Castells S, Hurwic M, Perel JM (1980): Estimation of monoamine and cyclic-AMP turnover and amino-acid concentrations of spinal fluid in autistic children. Neuropediatrics 11:250-255

Young JG, Cohen DJ, Brown SL, Caparulo BK (1978): Decreased urinary free catecholamines in childhood autism. J Am Acad Child Psychiatry 17:671-678

Young JG, Cohen DJ, Kavanagh ME, Landis HD, Shaywitz BA, Maas JW (1981): Cerebrospinal fluid, plasma and urinary MHPG in children. Life Sci 28:2837-2845

Yuwiler A, Oldendorf WH, Geller E, Braun L (1977): The effect of albumin binding and amino acid composition on tryptophan uptake into the brain. J Neurochem 28:1015-1023 